\title{
MARGINAL ADAPTATION AND FRACTURE RESISTANCE OF ENDOCROWN RESTORATIONS CONSTRUCTED FROM TWO CAD/CAM BLOCKS
}

\author{
Amira Mohamed Elsharkawy*
}

\begin{abstract}
Objective: The aim of this study was to evaluate the marginal adaptation and fracture resistance of endocrowns made from Lithium disilicate (Emax CAD) and CAD/CAM composite blocks (Brillient Crios) restoring mandibular premolars.

Materials and Methods: Fourteen extracted human single rooted mandibular premolars were endodontically prepared in a standardized way to receive CAD/CAM fabricated endocrowns, the samples were divided into two groups $(\mathrm{n}=7)$; E. max CAD (EM) group and Brillient Crios (BC) group. Marginal gaps $(\mu \mathrm{m})$ evaluated under stereomicroscope after cementation and repeated after thermocycling. Fracture load was recorded and Failure modes were determined by digital microscope and scanning electron microscope SEM.
\end{abstract}

Results: EM group verified higher vertical marginal gap mean value than $\mathrm{BC}$ either before or after thermocycling, the difference was statistically significant as indicated by two-way ANOVA ( $p>0.05)$. EM group recorded significantly higher fracture resistance mean values $(737.55 \pm 223.3 \mathrm{~N})$ than BC $(434.33 \pm 100.8 \mathrm{~N})$ group, $(\mathrm{p}<0.05)$ as verified by unpaired t-test. The failure mode presented that $(71.44 \%)$ of BC specimens exhibited favorable type and $(28.57 \%)$ catastrophic failure. Whereas, EM group revealed $(71.43 \%)$ catastrophic failure and (28.57\%) favorable type. Chi square test $(\mathrm{P}<0.05)$ displayed statistically significant difference between both groups.

Conclusions: Brilliant Crios endocrowns showed better marginal adaptation and more favorable failure mode than those fabricated from $\mathrm{E}$ max CAD. E max endocrowns revealed higher fracture resistance than Brillient Crios.

KEY WORDS: Marginal adaptation, fracture strength, premolar endocrown, Emax CAD, Brillient Crios.

\footnotetext{
* Associate Professor, Fixed Prosthodontics, Faculty of Dentistry, $6^{\text {th }}$ of October University, Giza, Egypt
} 


\section{INTRODUCTION}

Endocrowns are cautiously considered as substitute restorations for mutilated endodontically treated teeth (1) Initially advocated by Pissis (2) then defined by Bindl and Mormann ${ }^{(3)}$ as adhesive restorations involving core and crown as a sole unit with an extension in the pulp chamber, consequently it depends on macro-mechanical retention from the available pulpal chamber space and microretention through chemical adhesive cementation. (4) Previous studies ${ }^{(4,5)}$ demonstrated that restoring molars with endocrowns offer higher strength and fracture resistance during loading than molars repaired with conventional post, core and crowns. Earlier, in a clinical study; it was reported that $87 \%$ of posterior endocrowns recorded five year survival rate without debonding or failure. ${ }^{(6)}$ Endocrowns should also be examined for premolar teeth owing to its success in posterior teeth. In a clinical study, Bindl and Mörmann (7) assessed the exhibition of 208 endocrowns on premolars and molars, and discovered that the premolars offered more failures due to adhesion loss.

An imperious area of consideration is the restorative material selection to improve the bonding. Nowadays there are recent materials in the market with mechanical properties comparable to those of sound teeth and improve the bonding to the tooth structure. ${ }^{(8,9)}$

Developing resin-matrix for CAD/CAM blocks is considered to be an important approach for optimizing CAD/CAM materials. Hybrid materials are innovative materials can be divided into two subgroups rendering to their chemical compositions: materials that are predominantly based on ceramic; called Resin Nano Ceramic, and those mainly of resin matrix; called Nano hybrid composite. Brilliant Crios (BC) is a Nano hybrid composite blocks; an inventive new CAD/CAM material. Brillient Crios consists of about ( $71 \%$ by weight) inorganic filler grasping $20-\mu \mathrm{m}$ silica and $1-\mu \mathrm{m}$ barium glass in a highly cross linked methacrylate's matrix resulting in better marginal quality than glass ceramics ${ }^{(10)}$ and improving the dentin bonding. ${ }^{(8)} \mathrm{BC}$ has modulus of elasticity comparable to the dentin; which is much lower than ceramics, giving an exclusive biomechanical complex (monoblock) as the tooth and restoration become a single unit distributing the stress more evenly improving the flexural strength. (10) Moreover, controlled fabrication with constant thermal curing, gives the reinforced composite excellent mechanical properties that may sort them desirable for usage in areas with high occlusal forces ${ }^{(11)}$

Lithium disilicate ceramic is one of the allceramic systems used for monolithic restorations construction. It has a long term success because of its superior esthetics and greater physical properties, thus it has greater approval for anterior and posterior restorations. ${ }^{(7,9)}$

Increasing the marginal discrepancy leads to cement dissolution and leaks to the oral environment, plaque retention and alterations of the subgingival microflora signifying the gingival disease. Marginal adaptation measured one of the most imperative criteria disturbing the long term prognosis of ceramic restorations. ${ }^{(12)}$ Accordingly, more studies are always needed to discover the biomechanical behavior of modern materials when used as endocrowns before clinical trials. ${ }^{(13)}$ The purpose of this in vitro study was to evaluate the marginal adaptation and fracture resistance of CAD-CAM fabricated endocrowns restoring endodontically treated mandibular premolars using two different CAD/CAM blocks. The null hypothesis tested was that there would be no difference in the marginal adaptation or fracture resistance between endocrowns fabricated from the different tested materials.

\section{MATERIALS AND METHODS}

\section{Sample Size Calculation}

Sample size calculated depending on a previous study ${ }^{(14)}$ as a reference. According to this study, a 
sample size of 7 in each group has a $80 \%$ power to identify a difference between means of 77.59 with a significance level (alpha) of 0.05 (two-tailed). In $80 \%$ (the power) of those investigates, the $\mathrm{P}$ value will be less than 0.05 (two-tailed) so the results will be judged "statistically significant". In the remaining $20 \%$ of the experiments, the difference between means will be considered "not statistically significant".

\section{Teeth selection}

Fourteen human extracted, caries free singlerooted mandibular premolars were collected for the study. All teeth have comparable dimensions at the cemento-enamel junction (CEJ); mesio-distal width: $5.0 \pm 0.5 \mathrm{~mm}$; bucco-lingual: $7 \pm 1.3 \mathrm{~mm}$, and root length: $13 \pm 1.0 \mathrm{~mm}$ ) measured by a metal caliper. ${ }^{(15)}$ The adding conditions for the selected samples were absence of root cracks or fracture lines. The teeth were inspected using a magnifying lens below high light condition.

\section{Preparation of the teeth}

The crowns of the collected teeth were decoronated perpendicular to the long axis and $2 \mathrm{~mm}$ above the level of the cemento-enamel junction (CEJ) from the proximal surfaces using a diamond disc (Diamond discs 910P, Drendel+ Zweiling DIAMANT Gmbh, Germany) with a copious coolant.

\section{Endodontic Procedure:}

Endodontic reamers were used for dead pulp tissue removal, visual determination of working length; $1 \mathrm{~mm}$ shorter from the apical foramen. Rotary system Ni- Ti (Protaper, Dentsply, Switzerland) were used till F3 files size. 5\% sodium hypochlorite was used for irrigation between files. Paper points (Dentsply-Maillefer, Ballaigues, Switzerland) were used after irrigation for drying root canals. The prepared canal was fitted by trying a Master cone of a size F3 while using a tug-back action to reach the full working length. Gutta-percha points and resin sealer (ADSEAL, MetaBiomed, korea) were used for canal obturation. Excess gutta percha was removed with hot instrument till canal entrance and vertically condensed with a heated plugger. Pulp chamber floors were sealed with a thin layer of flowable composite material (Charmcore, Dentkist, Korea), to attain even pulp chamber floors at depths of $2 \mathrm{~mm}$ starting from the butt margin. Composite was light cured by (Elipar S10, 3M ESPE, Seefeld, Germany). The preparation depth was standardized for all specimens with periodontal probe and rubber stopper positioned taking the butt margin as reference point.

\section{Endocrown preparation}

All teeth were fixed along their long axis in orthodontic acrylic resin blocks consuming a round plastic mold using Dental surveyor, the roots were inserted in the resin blocks up to $2 \mathrm{~mm}$ under the CEJ similar to bone level. Using a special milling machine; Computerized Numerical Control milling machine (C.N.C Premium4820, imes-icore, Germany); a standardized cavity preparations were completed in all teeth; an oval retentive cavity with a depth of the pulp chamber. The preparations of internal walls were restricted to undercut removal with an internal taper of $8^{\circ}$ coronal divergence, using tapered diamond coated stainless-steel bur with a rounded end (G845KR, Edenta, Basel, Switzerland) held vertical to the pulpal floor. All internal line angles were rounded and smoothed with the same bur. The dimensions of an oval shaped cavity were (4.5mm bucco-linigual and $2.5 \mathrm{~mm}$ mesio-distal), ${ }^{11}$ (Figure1a). The axial walls were prepared from the pulpal side to provide for a standardized cavity wall thickness of $2.0 \pm 0.2 \mathrm{~mm}$ measured with a digital caliber (Mitutoyo IP65, Kawasaki, Japan). A temporary filling material (Cavit, 3M ESPE, Seefeld, Germany) was used for sealing the canal openings, teeth was kept in saline until endocrowns fabrication. 


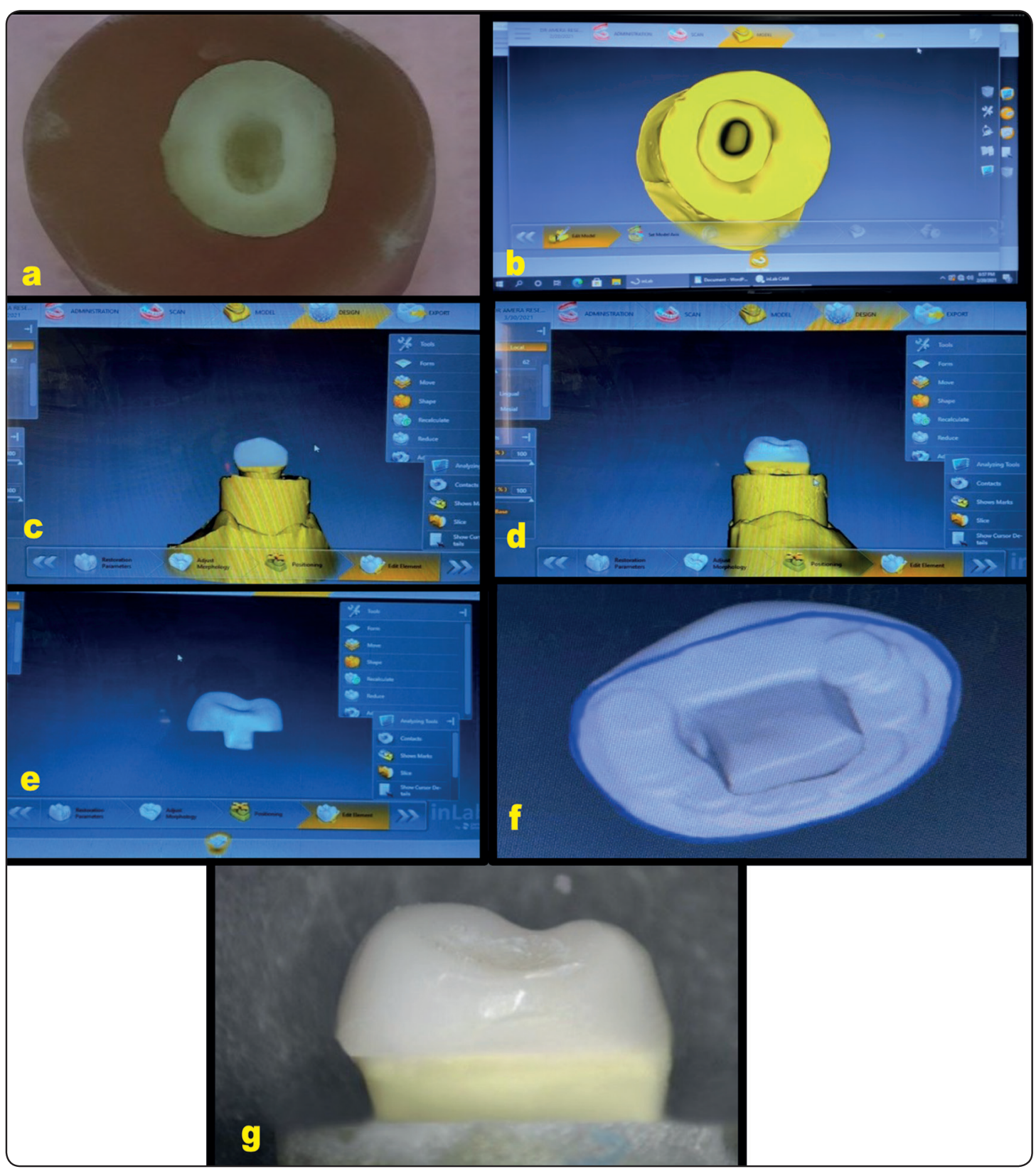

Fig. (1) a: Prepared teeth with $90^{\circ}$ butt margin, b: Scanned preparation into $360^{\circ}$ (virtual model for designing). c The proposed design for the endocrown (buccal view), d: Proximal view for the proposed design for the endocrown. e: The proposed fitting surface view of endocrown. f: The proposed proximal view of endocrown. G: Milled endocrown after cementation.

\section{Samples classification}

Teeth were randomly distributed into two equal groups, seven specimens each ( $\mathrm{n}=7)$, according to type of the material used for endocrowns construction:

- EM Group $(n=7)$ : endocrowns made with lithium disilicate (E.max Cad).

- BC Group ( $n=7)$ : endocrowns made with CADCAM reinforced composite blocks (Brillient Crios). The names, chemical compositions, and companies of the CAD/CAM materials tested are shown in Table 1. 
TABLE (1): The names, chemical compositions, and companies of the CAD/CAM materials tested:

\begin{tabular}{|l|l|l|l|}
\hline Brand & Type & Chemical composition & Manufacture \\
\hline Brilliant Crios & $\begin{array}{l}\text { Nano Hybrid } \\
\text { composite }\end{array}$ & $\begin{array}{l}\text { Organic part: cross-linked methacrylates } \\
\text { Inorganic part: } \\
\text {-overall } 71 \mathrm{wt} \%, \\
\text {-Barium glass with particle size }<1 \mu \mathrm{m} \\
\text {-Silica SiO2 with particle size , <20 nm }\end{array}$ & $\begin{array}{l}\text { Coltene Whaledent, } \\
\text { Altstatten, } \\
\text { Switzerland }\end{array}$ \\
\hline IPS e.max CAD & $\begin{array}{l}\text { Lithium disilicate } \\
\text { Glass Ceramic }\end{array}$ & $\begin{array}{l}\text { 97\% SiO2, Al2O3, P2O5, K2O, Na2O, CaO, F, 3\% } \\
\text { TiO2, and pigments, water, alcohol,Chloride }\end{array}$ & $\begin{array}{l}\text { Ivoclar Vivadent } \\
\text { Schaan, Liechtenstein }\end{array}$ \\
\hline
\end{tabular}

\section{Endocrown fabrication}

First, all teeth were sprayed using a Telescan light reflecting powder from Vita Zahnfabrik, Germany, to achieve optical impression of the sample. All teeth were scanned through CEREC In Lab scanner (InEos X5 Sirona, Germany). Endocrowns restorations were designed using the CEREC 3D software (version 4.3); an automatic margin detector was used to identify preparation margins. Restoration design parameters were standardized for all samples; mesio-distal distance between proximal contact areas were $6.8 \mathrm{~mm}$; distance between buccal and lingual faces were $8.9 \mathrm{~mm}$; height from the margin to the top of the buccal cusp was $7.5 \mathrm{~mm}$; height from the margin to the top of the lingual cusp was $6.8 \mathrm{~mm}$ ) and simulating the original occlusal anatomy; ${ }^{(9)}$ (Figure 1). This will assured standardization of load application point during testing, with 80 micron spacer parameter. Endocrowns were milled via Cerec MCX5 (Sirona, Bensheim, Germany). After milling, the EM endocrowns were exposed to a heating procedure for crystallization and glazing, (Programat P300; Ivoclar Vivadent). While, GC ultimate finishing and polishing kit (GC polishing kit America Inc. USA) and polisher paste (GC DiaPolisher Paste America Inc USA) were used for $\mathrm{BC}$ endocrowns polishing as recommended by the manufacturer.

\section{Endocrowns Cementation}

Before cementation, endocrowns fitting surfaces were treated following to the manufacturers' instructions. The fitting surfaces of EM endocrowns were etched for $20 \mathrm{sec}$ by 5\% IPS Ceramic Etching Gel (Ivoclar Vivadent, Liechtenstein); while the fitting of $\mathrm{BC}$ endocrowns were sandblasted with 50 $\mu \mathrm{ml}_{2} \mathrm{O}_{3}$ powder $(0.15 \mathrm{MPa} / 1.5$ bar pressure, with $10 \mathrm{~mm}$ distance). Endocrowns fitting surfaces were coated with silane coupling agent (Bisco, USA) and left to dry for $60 \mathrm{sec}$, then an adhesive agent (All Bond Universal, Bisco, USA) was applied for $60 \mathrm{sec}$ and permitted to dry.

With a low-speed cleaning brush in a low speed hand piece; (Dentsply, York, USA) and an aqueous suspension of pumice, all the samples (teeth) were cleaned for $20 \mathrm{sec}$ followed by air-water spray flushing for $20 \mathrm{sec}$ then dried with oil free air. ${ }^{(16)}$

All samples were luted using dual cure adhesive resin cements (RelyX U200, 3M ESPE Dental Products St. Paul, USA) under constant load (3 $\mathrm{kg}$ load) for 5 minutes using a specially milled loading device. The excess cement was detached then light cured for $20 \mathrm{sec}$ for each side. After one day cementation and storage in distilled water, the cervical vertical marginal gaps were evaluated.

\section{Marginal Gap Measurements}

Measurements of the cervical vertical marginal gap were completed after cementation. For each specimen, under stereomicroscope (MA 100 Nikon, Japan) four equidistant marks in each surface (Mesial, distal, labial, and lingual), were engraved on the tooth $1 \mathrm{~mm}$ below the margin using size $1 / 2 \mathrm{~mm}$ round bur to allow measurements at the same 
points every time. Four stereo-micrographs were taken for each tooth, under 100X magnification. All images were conveyed to the computer system for analysis. Using the software (Omnimet, Buehler, USA) for image analysis, vertical gaps between the cervical margin of the endocrown and the outer end of the butt margin at four equidistant points were measured in each tooth surface, so sixteen points were collected for each tooth. All data were arranged in excel sheet and the mean vertical gap (in $\mu \mathrm{m}$ ) for each specimen was then calculated, formulated for statistical analysis, (Figure 2).

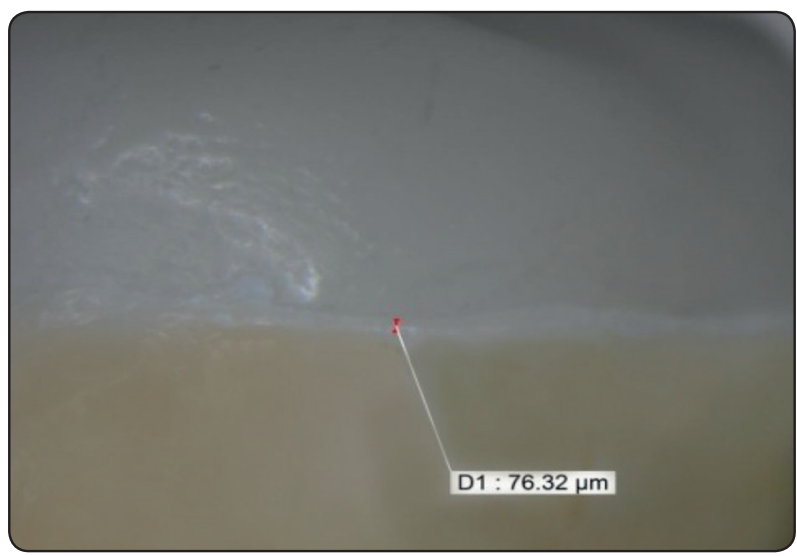

Fig. (2): Vertical Marginal gap assessment with a virtual ruler.

\section{Thermomechanical Cycling}

All samples were thermo-cycled for 5000 cycles between $5^{\circ}$ and $55^{\circ}$ with the dwell time of $30 \mathrm{sec}$ dwell time in a thermal cycling machine (The 100 SD Mechatronic Thermocycler, Germany)

\section{Marginal Gap Measurements}

Vertical gaps were measured again after the thermocycling using the same method described previously.

\section{Fracture Resistance Testing}

All samples were individually secured on a lower compartment of computer-controlled material testing machine (Instron universal testing machine model 3345 England) by tightening screws. Fracture test was done by compressive mode of load applied occlusally using a metallic rod with spherical tip $(5.8 \mathrm{~mm}$ diameter) representing the antagonist tooth attached to the upper movable compartment of testing machine moving at cross-head speed of $1 \mathrm{~mm} / \mathrm{min}$. (Figure 3 ). The fracture load required to cause the specimen failure, was recorded in Newton $(\mathrm{N})$, which was indicated as a peak in the loaddisplacement mapping.

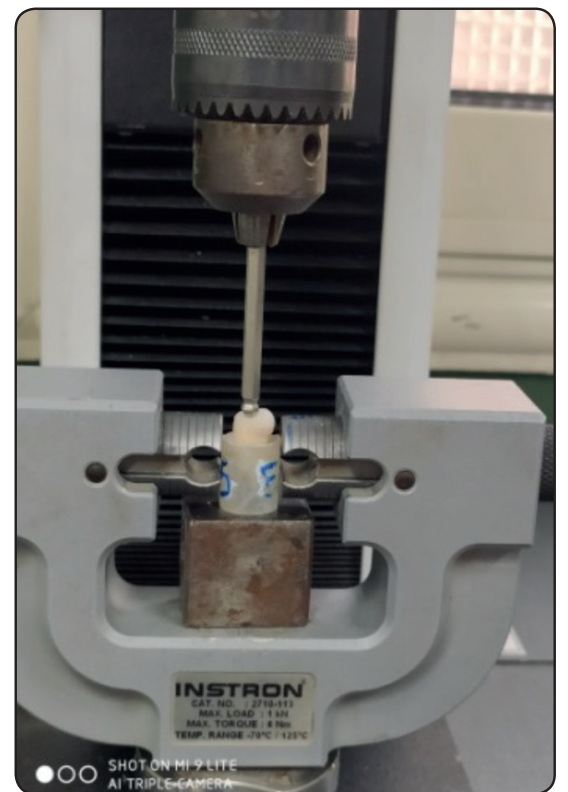

Fig. (3): Sample mounted on a computer-controlled material testing machine.

\section{Fracture Mode}

Following the fracture resistance test, fracture mode for all samples were inspected visually, by Digital microscope (U500x Digital microscope, Guangdong, China) and scanning electron microscope (SEM) (JEOL JSMT 20. Japan) operating at $20.0 \mathrm{Kv}$, at $(50 \mathrm{X})$ for fracture pattern examination. Regarding to digital microscope; each sample was snapped using USB Digital microscope with a built in camera connected with a compatible personal computer using a fixed magnification of X36.

Specimens were categorized according to the following descriptions ${ }^{(17)}$

-• Type I: De-bonding of the endocrown (complete or partial debonding) without fracture (favorable failure). 
- Type II: Endocrown fracture only without tooth fracture (favorable failure).

- Type III: fracture of the endocrowns or tooth structure above the level of Cemento-enamel junction (favorable failure).

- Type IV: fracture of the endocrowns or tooth structure below the level of Cemento-enamel junction (Non-favorable or catastrophic failure).

\section{Statistical Analysis}

The results were analyzed using Graph Pad Instat (Graph Pad, Inc.) software for windows. A value of $\mathrm{P} \leq 0.05$ was considered statistically significant. Continuous variables were expressed as the mean and standard deviation. After homogeneity of variance and normal distribution of errors had been confirmed, student t-test was done for compared pairs. Two-way ANOVA was done to detect effect of each variable (material and aging). Chi square test was performed for failure mode analysis. Sample size $(n=7)$ was large enough to detect large effect sizes for main effects and pair-wise comparisons, with the satisfactory level of power set at $80 \%$ and a $95 \%$ confidence level.

\section{RESULTS}

\section{Marginal gap before and after thermocycling}

The mean values and standard deviation of marginal gap $(\mu \mathrm{m})$ as function of material group type and (before and after) thermal aging are summarized in Table 2 and graphically drawn in Figure 4.

Regards to the materials without taking into consideration thermocycling; $\boldsymbol{E M}$ group recorded statistically significant $(\mathrm{p}<0.05)$ higher vertical marginal gap mean values than group $\boldsymbol{B C}$, as shown by Two-way ANOVA. While thermocycling affected the vertical marginal gap mean values significantly $(\mathrm{p}<0.05)$ regardless of material type; where the marginal gap after thermocycling recorded higher mean value than before as demonstrated by two-way ANOVA, Table 2 and Figure 4.

Regards to the total vertical marginal gap distance either before or after thermocycling; $\boldsymbol{E M}$ group recorded higher gap mean values than $\boldsymbol{B C}$ group. This was statistically significant $(\mathrm{p}<0.05)$ as verified by unpaired t-test. It was noted that BC group after thermocycling recorded statistically nonsignificant $(\mathrm{p}>0.05)$ higher gap mean values than before. This difference was as revealed by paired t-test. While for EM group there was a statistically significant $(\mathrm{p}<0.05)$ increase in the marginal gap after thermocycling than before as demonstrated by paired t-test - Table 2 and Figure 4.

TABLE (2): Marginal gap results mean values \pm SDs $(\mu \mathrm{m})$, as a function of material group type and thermal aging.

\begin{tabular}{|c|c|c|c|c|c|c|c|c|}
\hline \multirow{4}{*}{\multicolumn{2}{|c|}{ Variable }} & \multicolumn{6}{|c|}{ Thermo-cycling } & Statistics \\
\hline & & \multicolumn{3}{|c|}{ Before } & \multicolumn{3}{|c|}{ After } & \\
\hline & & \multirow{2}{*}{$M e a n \pm S D$} & \multicolumn{2}{|c|}{$95 \% C I$} & \multirow{2}{*}{$M e a n \pm S D$} & \multicolumn{2}{|c|}{$95 \% C I$} & \\
\hline & & & Low & High & & Low & High & \\
\hline \multirow{2}{*}{ Material } & $B C$ & $50.58 \pm 4.81$ & 46.13 & 55.03 & $56.11 \pm 4.88$ & 51.59 & 60.62 & $0.0541 \mathrm{~ns}$ \\
\hline & $E M$ & $62.87 \pm 1.95$ & 61.08 & 64.67 & $70.72 \pm 2.29$ & 68.61 & 72.64 & $<0.0001^{*}$ \\
\hline Statistics & $P$ value & \multicolumn{3}{|c|}{$<0.0001 *$} & \multicolumn{3}{|c|}{$<0.0001 *$} & \\
\hline
\end{tabular}

*; significant $(p<0.05) \quad$ ns; non-significant $(p>0.05)$ 


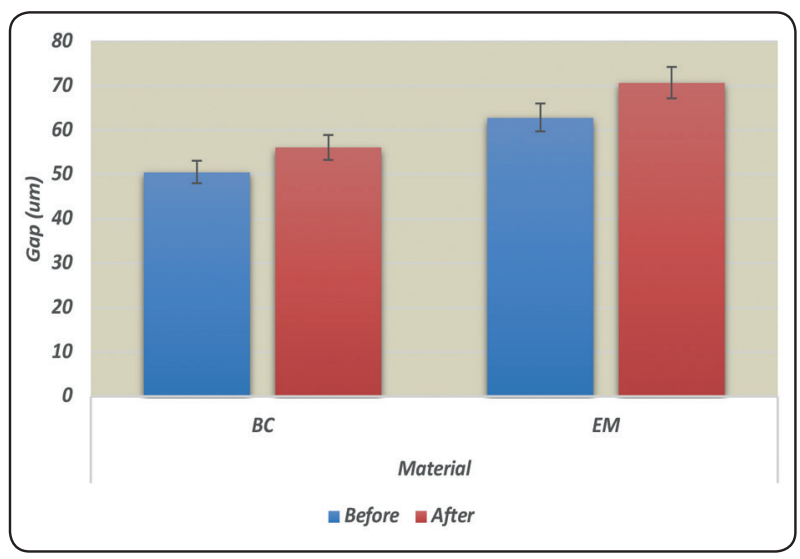

Fig. (4): Column chart comparing total marginal gap mean values $(\mu \mathrm{m})$ as function of material group.

\section{Fracture resistance}

Fracture resistance results (Mean $\pm \mathrm{SD}$ ) measured in Newton (N) as function of material group after thermal aging are summarized in Table 3 and graphically drawn in Figure 5. It was found that $\boldsymbol{E M}$ group recorded higher fracture mean values than $\boldsymbol{B C}$ group. This was statistically significant $(\mathrm{p}<$ 0.05 ) as verified by unpaired t-test.

TABLE (3): Comparison between fracture resistances (N) as function of material group after thermal aging.

\begin{tabular}{|c|c|c|c|c|c|}
\hline \multirow{2}{*}{ Variable } & \multirow{2}{*}{ Mean \pm SD } & \multicolumn{2}{c|}{$95 \%$ CI } & Statistics \\
\cline { 4 - 6 } & & Low & High & \multirow{2}{*}{ P value } \\
\hline \multirow{3}{*}{ Material } & BC & $\mathbf{4 3 4 . 3 3 \pm 1 0 0 . 8}$ & 341.1 & 527.6 & \multirow{2}{*}{$0.007 *$} \\
\cline { 3 - 5 } & EM & $\mathbf{7 3 7 . 5 5} \pm \mathbf{2 2 3 . 3}$ & 531.0 & 944.1 & \\
\hline
\end{tabular}

ns; non-significant $(P>0.05) \quad$ *; significant $(P<0.05)$

\section{Failure mode}

Frequent distribution of failure modes scores (\%) for both groups are summarized in Table 4 and graphically drawn in Figure 6.

The results displayed that $71.42857 \%$ of $\boldsymbol{B C}$ specimens exhibited favorable fracture type (repairable) and 28.57143\% non-favorable (catastrophic) fracture type. High prevalence of catastrophic facture $71.42857 \%$ was revealed by $\boldsymbol{E M}$ group and $28.57143 \%$ favorable failure mode (Figure 7). The difference between both groups was statistically significant as indicated by chi square test $(\mathrm{P}<0.05)$, (Figure 7).

TABLE (4): Frequent distribution of failure modes scores (\%) for both groups.

\begin{tabular}{|c|c|c|c|c|}
\hline \multirow{2}{*}{ Variable } & \multicolumn{2}{|c|}{ Failure mode } & Statistics \\
\cline { 3 - 5 } \multicolumn{2}{|c|}{} & favorable & Non-favorable & P value \\
\hline \multirow{3}{*}{ Material } & $B C$ & $5(71.42857 \%)$ & $2(28.57143 \%)$ & \multirow{2}{*}{$<0.0001 *$} \\
\cline { 2 - 4 } & $\boldsymbol{E M}$ & $2(28.57143 \%)$ & $5(71.42857 \%)$ & \\
\hline
\end{tabular}

ns; non-significant $(P>0.05) \quad$ *; significant $(P<0.05)$

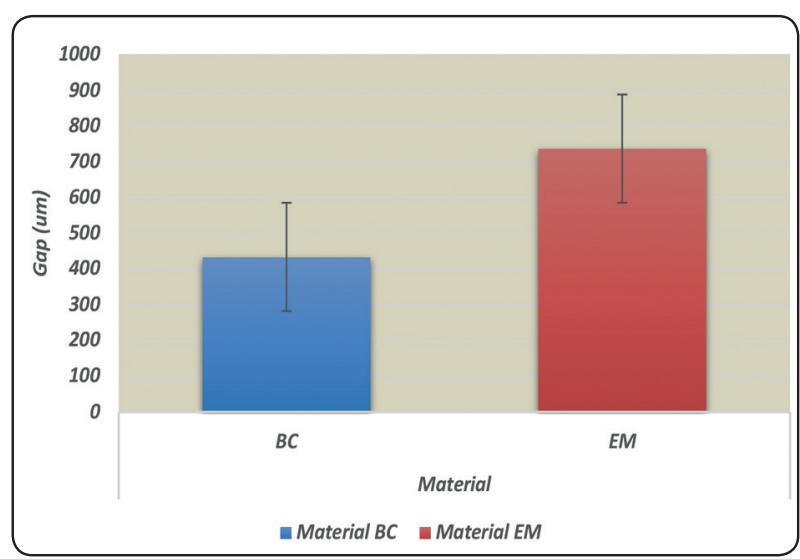

Fig. (5): Column chart of fracture resistance mean values $(\mathrm{N})$ as a function of material group.

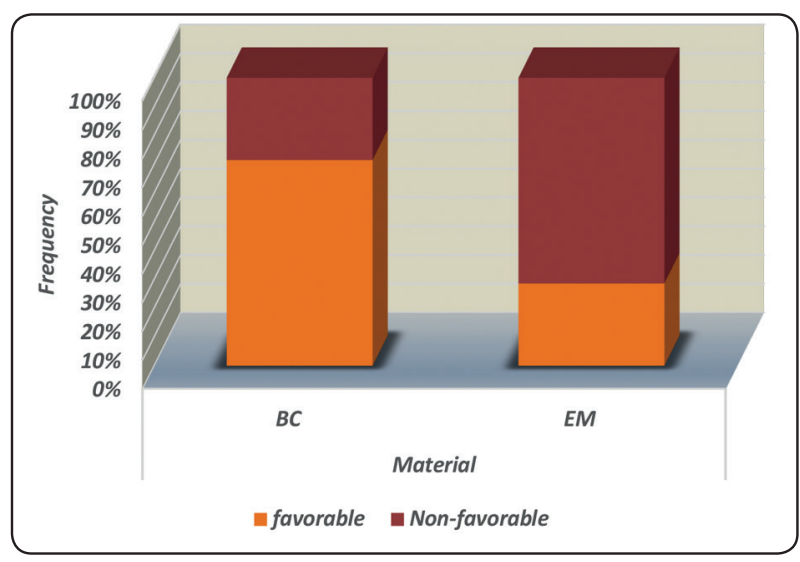

Fig. (6): Column chart comparing total marginal gap mean values $(\mu \mathrm{m})$ as function of material group. 


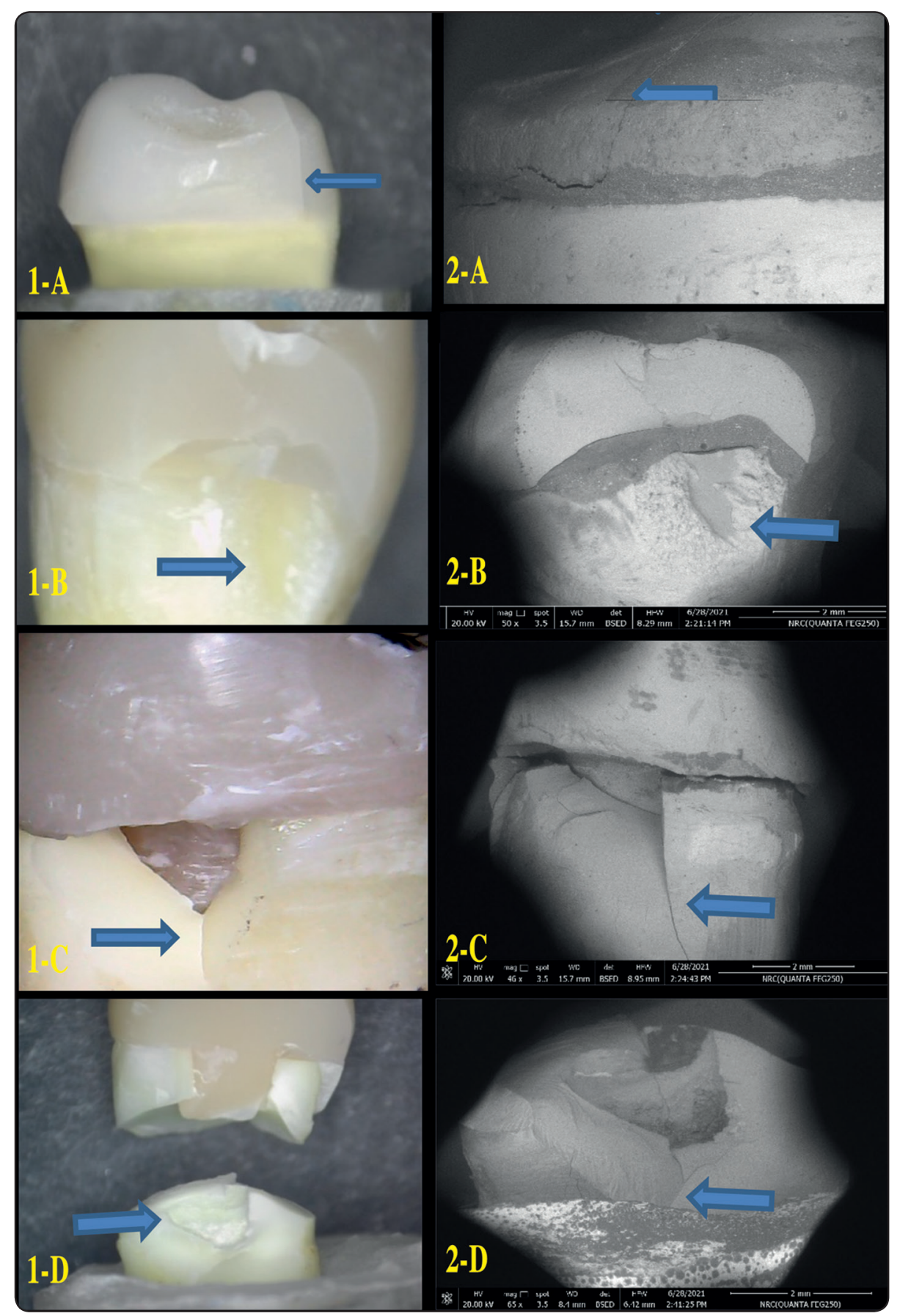

Fig. (7): (A) Digital microscope photograph (X36), (B) Scanning electron microscope SEM (X 50) of the four types of failure. (1-A) and (1-B): fracture of the EM endocrown without fracture of the tooth (favorable failure). (2-A) and (2-B): fracture of the $\mathrm{BC}$ endocrowns and tooth above the $\mathrm{CEJ}$ (favorable failure). (3-A) and (3-B): fracture of the tooth only below the CEJ (un-favorable failure) in BC endocrown. (4-A) and (4-B): complete fracture of the BC endocrown and tooth complex below the CEJ (catastrophic failure). 


\section{DISCUSSION}

Endocrowns take advances of the modern developments in adhesives, ceramics, and CAD/CAM technology. ${ }^{(1,6,7)}$ Several studies ${ }^{(8,9)}$ demonstrated the satisfactory performance of endocrowns restoring molars regarding esthetics and fracture strength. Consequently, studies have a duty to discover the biomechanical performance of modern materials while used as endocrowns for premolar teeth. Additionally, success of any restoration depends on the fracture resistance and marginal adaptation (3, 4). Accordingly, it was necessary to investigate the marginal accuracy and fracture resistance of different endocrown materials one of them is inventive new Cerec material. The results of the current study presented that, the type of the material considerably affected the fracture resistance and vertical marginal gap of endocrown restorations so the null hyposethis of this study was rejected.

Extracted human teeth were used in the present study; to be similar to the clinical condition concerning the enamel and dentin bonding, strength, pulp chambers contours and an elastic modulus of hard dental tissue to imitate force distribution on radicular part of the tooth structure. ${ }^{(1)}$

Mandibular premolars were chosen in this study to evaluate the attainment of endocrowns with different materials restoring such teeth with special morphology and unique anatomy which are susceptible to cusp deflection and fracture under occlusal loads. ${ }^{(17)}$

The type and curvature of finish line are factors that might affect vertical marginal gap. The butt margin design used in this study provides a configuration without complexity. ${ }^{(18)}$ Additionally, this in-vitro study mimics the compromised condition of extensive tooth loss, which does not freely allow for use the ferrule effect in crown preparation. ${ }^{(19)}$

This study used a standardized pulp-chamber depth of $2 \mathrm{~mm}$, as recommended by Hayes et al. (20) who described that molar teeth restored with endocrowns having $2 \mathrm{~mm}$ pulp extension revealed higher fracture strength than teeth with deeper cavities, authors added that, endocrowns with deep pulpal extensions tend more to irreparable fractures.

$\mathrm{CAD} / \mathrm{CAM}$ technology was chosen in this study for standardization the restoration thickness, geometry and cuspal inclines during fabrication; consequently, the area of load application during testing. ${ }^{(17)}$

IPS Emax CAD blocks were chosen as a control because they have the advantages of long term clinical success, good bonding characteristics, satisfactory esthetics and high strength. ${ }^{(21)}$

The virtual die spacer was set at $80 \mu$ because the preparation was completed with an internal taper of $8^{\circ}$ coronal divergence, this would cause excessive stress on the endocrowns if less relief was chosen. ${ }^{(22)}$

In order to simulate the clinical conditions to which the restorations will be subjected, thermal cycling was carried out; 5000 cycle program from $5^{\circ} \mathrm{C}$ to $55^{\circ} \mathrm{C}$, which represents six months clinical service. ${ }^{(23)}$

In this study, static loading was assessed by applying an axial force at a 90-degree angle along the long axis because lateral forces are always accompanied with axial forces during chewing function. ${ }^{(13,24,25)}$

In the current study, marginal fit was evaluated by direct viewing with external measurements using the stereomicroscope. This technique has the benefits of non-invasive, precise and reproducible measurements therefore, is useful to determine the accurate fit of the entire specimen margins. ${ }^{(26,27)}$

Results of the current study revealed that, EM group demonstrated higher vertical marginal gap mean values than $\mathrm{BC}$ group, either before or after thermo-cycling. This was statistically significant $(\mathrm{p}$ $<0.05)$ as verified by unpaired t-test. The marginal discrepancy values were found within clinically accepted borders in both groups where it was less 
than $120 \mu \mathrm{m}$ as reported by several studies. ${ }^{(28,29)}$ The findings were in agreement with Mohammed and Majeed (30) whom reported better marginal adaption of Brillient Crios than lithium disilicate overlay restorations. This might be attributed to the difference in the post-milling handling of both $\mathrm{CAD} /$ CAM materials; that lithium disilicate requisite an additional step (post-milling crystallization) to reach supreme esthetic and maximum mechanical properties. Gold et al. ${ }^{(31)}$ reported that $0.2 \%-0.3 \%$ shrinkage of lithium disilicate restorations after crystallization firing which produced an increase in the marginal gap. Kim et al. ${ }^{(32)}$ examined internal and marginal adaptation of E- max CAD crowns before and after crystallization firing. The authors reported statistically significant differences in marginal and internal gap measurements in all areas before and after crystallization but within the clinically acceptable gap range.

Additionally, this result is probably due to the reduced brittleness of $\mathrm{BC}$ materials compared with lithium disilicates (LD) ceramics. This increased hardness caused difficulty in milling of LD with more time needed which could increase the marginal discrepancy. ${ }^{(33)}$ Besides, the hardness of lithium disilicate might cause wearing of $\mathrm{CAD} / \mathrm{CAM}$ milling burs, since the continuous milling may affect the cutting ability of the burs, subsequently, led to increase marginal discrepancies as demonstrated by Azarbal et al. ${ }^{(34)}$ who investigated the marginal fit of two CAD/CAM materials: lithium disilicate and hybrid ceramic. The results found that, after continuous milling of fifteen coping of lithium disilicate group, the marginal gap was had a significant increase from ninth to fifteenth coping with a $132 \mu \mathrm{m}$ mean value for the coping number fifteen. The Authors described these outcomes to tiring away the milling burs consequently decreasing cutting accuracy; therefore they advocated that, the bur should be changed after milling of eight lithium disilicate coping in contrary to manufacturer recommendations. ${ }^{(34)}$ Previous studies ${ }^{(35,36)}$ found that composite based CAD-CAM restorations recorded higher marginal stabililty during milling than ceramics based materials; authors attributed this to the greater edge chipping resistance of composite based than ceramic based materials.

Thermocycling aging in the present study lead to significant $(\mathrm{p}<0.05)$ increase in the vertical marginal gap mean values regardless of material type, as demonstrated by two-way ANOVA; this comes in agreement with Hung et al. ${ }^{(37)}$ who demonstrated a significant negative influence of thermal cycling on marginal fit of ceramic crowns. Also, Krejci et al. ${ }^{(38)}$ stated significant negative consequences of thermal cycling on the marginal integrity of adhesively lute crowns. This might be due to failure of the cement- interfaces as a result of significant stresses produced by thermocycling. The differences in thermal expansion between cement and tooth or restoration and the repetition may further contribute to the deterioration of the marginal adaptation. ${ }^{(39)}$ However, Beschnidt and Strub ${ }^{(40)}$ mentioned that there was no significant effect of aging procedure on the marginal fit.

In the present study, Emax group revealed statistically higher fracture resistance than BC group. This result might be attributed to the differences in the mechanical properties, chemical composition and microstructure of both materials. E max CAD material has high mechanical properties including high flexural strength (360MPa) and high fracture toughness $\left(2.25 \mathrm{MPa} \mathrm{m}^{1 / 2}\right)$ as compared with $\mathrm{BC}$ material which has low flexural strength (198 MPa) and low fracture toughness $\left(1.5 \mathrm{MPa} \mathrm{m}^{1 / 2}\right)$. Also the presence of needle shaped crystalline particles in the lithium disilicates (LDS) increases the fracture resistance against loading as better counters the load than the dispersed spherical charge in resin Nano composite (RNC), ${ }^{(41)}$ it might be also explained by good adhesive properties and high resistance to dislodgment of LDS ceramic due to its acid-etching. ${ }^{(42)}$

The results of this in-vitro study were in accordance with other studies ${ }^{(43-45)}$ which presented that lithium disilicate glass ceramics had the highest 
fracture resistance, than Nano Hybrid Composites. Altieret al. ${ }^{(43)}$ found that LDS (IPS emax CAD) molar endocrowns; recorded higher fracture strength than Resin Nano Composite (Solidex and Grandia), respectively under axial loading. Naffah et al (44) demonstrated higher fracture resistance of lithium disilicate and Enamic crowns than Brilliant Crios and Cerasmart.

On the other hand, Emam and Aleem ${ }^{(45)}$ presented dissimilar results; they examined the fracture resistance of occlusal veneers fabricated from Brillient Crios, Vita Enamic and lithium disilicate after cyclic fatigue loading, authors found that Brillient Crios presented the statistically significantly highest mean fracture resistance than Vita Enamic and lithium disilicate. Authors attributed this result to the presence of polymers in the microstructure of hybrid ceramics has made them more resistance to crack propagation than their conventional ceramic counterparts. ${ }^{(46)}$

In the current study, the mean fracture loads for both tested groups were more than the mean fracture load reported by several studies ${ }^{(49)}(322.5 \mathrm{~N})$ in the premolar region. The higher mean value of fracture resistance in EM group was $(737.55 \pm 223.3 \mathrm{~N})$, while the lower mean value of fracture resistance in BC group was $(434.33 \pm 100.8 \mathrm{~N})$.

Digital microscope and SEM (Figure7) were used for evaluating the failure mode in the present study. BC group recorded (71.42857\% favorable failure mode and $28.57143 \%$ catastrophic failure). Meanwhile, EM group recorded (28.57143\% favorable mode and $71.42857 \%$ catastrophic failure). The difference between both groups was statistically significant as indicated by chi square test $(\mathrm{P}<0.05)$. It was noted that catastrophic failures in E-max group were at loads higher than recorded under masticatory function. These results were in agreement with other studies. ${ }^{(47,48)}$ This could be attributed to the rigidity of E-max (Lithium-disilicate) and its higher modulus of elasticity (95 GPa) than $\mathrm{BC}$, which concentrates strain in weak area leads to catastrophic fractures. ${ }^{(48)}$ The low modulus of elasticity of BC (10 GPa) gives them an affinity to curve under loading and dispense strain more evenly. Both the restoration and underlying dentin undergo a parallel degree of plastic deformation, leading to transmission of the applied load to the underlying dentin rather than accumulating in the restoration. ${ }^{(13)}$

\section{CONCLUSIONS}

Within the restrictions of this study, the subsequent conclusions could be withdrawn:

1. The endocrowns restorations constructed from Brilliant Crios blocks showed better marginal adaptation and more favorable failure than those fabricated from E max CAD.

2. The E-max endocrowns showed higher fracture resistance than Brillient Crios endocrowns.

3. The vetical marginal gap of E-max CAD and Brillient Crios endocrowns fall within the clinical acceptable range.

4. E-max CAD and Brillient Crios CAD/CAM materials showed fracture loads above the recommended minimum fracture load for premolar region.

\section{REFERENCES}

1. Chang CY, Kuo JS, Lin YS and Chang YH; Fracture resistance and failure modes of CEREC endo-crowns and conventional post and core-supported CEREC crowns Journal of Dental Sciences: 2009; 4(3) 110-117.

2. Pissis P: Fabrication of a metal-free ceramic restoration utilizing the monobloc technique Practical Periodontics \& Aesthetic Dentistry: 1995; 7(5) 83-94.

3. Bindl A and Mörmann WH: Clinical evaluation of adhesively placed Cerec endocrowns after 2 yearsPreliminary results Journal of Adhesive Dentistry: 2009; 1(3)255-265.

4. Mörmann WH, Bindl A, Lu“ thy H, and RathkeA: Effect of preparation and luting system on all-ceramic computergenerated crowns International Journal of Prosthodontics; 2009; 11(4) 333-339. 
5. Morgano SM, Hashem AF, Fotoohi K and Rose L. A nationwide survey of contemporary philosophies and techniques of restoring endodontically treated teeth. J Prosthet Dent. 1994; 72(3):259-267.

6. Tzimas K, Tsiafitsa, Gerasimou $\mathrm{P}$ and Tsitrou E: Endocrown restorations for extensively damaged posterior teeth: clinical performance of three cases Restor Dent Endod. 2018; 43(4):e38

7. Bindl A, Richter B and Mormann WH.: Survival of ceramic computer-aided design/manufacturing crowns bonded to preparations with reduced macroretention geometry. Int $\mathbf{J}$ Prosthodont 2005; 18(3):219-224.

8. Lin CL, Chang YH and Pai CA.: Evaluation of failure risks in ceramic restorations for endodontically treated premolar with mod preparation. Dent Mater 2011; 27(5):431-438.

9. Guo J, wang, Li X. et al: A comparison of the fracture resistances of endodontically treated mandibular premolars restored with endocrowns and glass fiber postcore retained conventional crowns J Adv Prosthodont 2016;8:489-93

10. Helvey GA. Chairside CAD/CAM - Lithium-disilicate restoration for anterior teeth made simple. Inside Dentistry. 2009; 5: 58-67.

11. Awada A. and Nathanson D.: Mechanical properties of resin-ceramic CAD/CAM restorative materials. The Journal of prosthetic dentistry, 2014; 114 (4): 587-593.

12. Matzinger $M$, Hahnel $S$, Preis $V$ and Rosentritt $M$ : Polishing effects and wear performance of chairside CAD/ CAM materials. Clin Oral Investig. 2018; 23:725-737.

13. Glossary of Prosthodontic Terms. J Prosthet Dent. 2005; 94(1):10- 92.

14. Acar D H and Kalyoncuoğlu E: The fracture strength of endocrowns manufactured from different hybrid blocks under axial and lateral forces; Clinical Oral Investigations, 2020 .

15. PedrolloLise D, Van Ende A, De Munck J, Umeda Suzuki T, Cardoso Vieira L and Van Meerbeek B. Biomechanical behavior of endodontically treated premolars using different preparation designs and CAD/CAM materials. J Dent. 2017; 59: 54-61.

16. El-Damanhoury HM and Gaintantzopouloub M: The effect of immediate dentin sealing and optical powder removal method on the fracture resistance of $\mathrm{CAD} /$ CAM fabricated endocrowns; International Journal of Computerized Dentistry 2016;19(2):135-151
17. El-Damanhoury HM and RN Haj-Ali JA Platt: Fracture Resistance and Microleakage of Endocrowns Utilizing Three CAD-CAM Blocks Operative Dentistry, 2015, 402, 201-210.

18. Burke FJ. Tooth fracture in vivo and in vitro. J Dent. 1992; 20(3):131-9.

19. De Kuijper MCFM, Cune MS, Tromp Y, Gresnigt MMM. Cyclic loading and load to failure of lithium disilicate endocrowns: Influence of the restoration extension in the pulp chamber and the enamel outline. J Mech Behav Biomed Mater. 2020; 105: 103670.

20. Hayes A, Duvall N, Wajdowicz M, Roberts H : Effect of endocrown pulp chamber extension depth on molar fracture resistance. Oper Dent; 2004 42:327-334.

21. Santos G. C., Santos M.J.M.C, Rizkalla,A. S., Madani D.A. and El-Mowafy O.,. Overview of CEREC CAD/ CAM chairside system. Gen Dent., 2013; 61 (1): 36-40.

22. Liu B, Lu C, et al. The effects of adhesive type and thickness on stress distribution in molars restored with allceramic crowns. J Prosthodont . 2011; 20(1):35-44.

23. Nawafleh N, Hatamleh M, Elshiyab S and Mack F, Lithium Disilicate Restorations Fatigue Testing Parameters: A Systematic ReviewJournal of Prosthodontics. 2016, 25: 116-126.

24. Ghajghouj $\mathrm{O}$ and FarukS T; Evaluation of Fracture Resistance and Microleakage of Endocrowns with Differerent Intracoronal Depths and Restorative Materials Luted with Various Resin Cements. Materials 2019, 12, 2528.

25. Al-Shibri $\mathrm{S}$ and ElguindyJ: Fracture Resistance of Endodontically Treated Teeth Restored With Lithium Disilicate Crowns Retained With Fiber Posts Compared To Lithium Disilicate and Cerasmart Endocrowns: In Vitro Study; Dentistry .2017; 12, p464.

26. Julide $\mathrm{O}$, Cumhur $\mathrm{S}$, Alper $\mathrm{C}_{s}$. The effect of aged dental ceramics on gingival cell viability. Hacettepe Dis, Hekimli_gi Fak€ultesi Dergisi. 2006;30: 102-107.

27. Att H, Komine F, Gerds T, Strub J. Marginal adaptation of three different zirconium dioxide three unit fixed dental prostheses. J Prosthet Comlekoglu Dent. 2009; 101: 239-47.

28. Scherrer SS, de Rijk WG, et al. Effect of cement film thickness on the fracture resistance of a machinable glassceramic. Dent Mater 1994;10(3):172-177. 
29. McLean JW, von Fraunhofer JA. The estimation of cement film thickness by an in vivo technique. Braz Dent J. 1971; 131:107-11.

30. Mohammed HZ, Majeed AM: effect of cementation protocol on the marginal adaptation of indirect overlay restorations fabricated from two different all-ceramic cad/ cam materials. Journal of research in medical and dental science. 2020 , volume 8 , issue 7 , page no: $518-525$

31. Gold SA, Ferracane JL, da Costa J. Effect of crystallization firing on marginal gap of CAD/CAM fabricated lithium disilicate crowns. J Prosthodont 2018; 27:63-66.

32. Kim JH, Oh S, Uhm SH. Effect of the crystallization process on the marginal and internal gaps of lithium disilicate CAD/CAM crowns. Bio Med Res Int 2016; 2016 .

33. Yara A, Goto SI, Ogura H. Correlation between accuracy of crowns fabricated using CAD/CAM and elastic deformation of CAD/CAM materials. Dent Material J 2004; 23:572-576.

34. Azarbal A, Azarbal M, Engelmeier RL, et al. Marginal fit comparison of CAD/CAM crowns milled from two different materials. J Prosthodont. 2018; 27:421-428.

35. Argyrou R, Thompson GA, Cho SH: Edge chipping resistance and flexural strength of polymer infiltrated ceramic network and resin nanoceramic restorative materials. J Prosthey Dent. 2016,116:397-403.

36. Quinn GD, Giuseppetti AA, Hoffman Kh: Chipping fracture resistance of Dental CAD/CAM restorative materials: part I-procedures and results.2014: Dent Mater; 30: 99-111.

37. Hung SH, Hung KS, Eick JD, et al. Marginal fit of porcelain-fused-to metal and two types of ceramic crowns. J Prosthet Dent. 1990; 63 (1):26-31.

38. Krejci I, Mueller E, Lutz F. Effects of thermocycling and occlusal force on adhesive composite crowns. J Dent Res. 1994; 73(6):1228- 1232.

39. Rosentritt M, Sikora M, Behr M, Handel G. In vitro fracture resistance and marginal adaptation of metallic and tooth-coloured post systems. J Oral Rehabil. 2004; 31(7):675-681.
40. Beschnidt SM, Strub JR. Evaluation of the marginal accuracy of different all-ceramic crown systems after simulation in the artificial mouth. J Oral Rehabil. 1999; 26(7):582-593.

41. Shor A, Nicholls JI, Phillips KM, \& Libman WJ :Fatigue load of teeth restored with bonded direct composite and indirect ceramic inlays in MOD class II cavity preparations; International Journal of Prosthodontics: 2003; 16(1) 64-69.

42. Dere M, Ozcan M, \& Gohring TN: Marginal quality and fracture strength of root-canal treated mandibular molars with overlay restorations after thermocycling and mechanical loading Journal of Adhesive Dentistry: 2004; 12(4). 287-294.

43. Altier M, Erol F, Yildirim G, Dalkilic EE. Fracture resistance and failure modes of lithium disilicate or composite endocrowns. Niger J Clin Pract. 2018; 21(7): 821-826.

44. NaffahN, Hani Ounsi2, Mutlu Ozcan3, Hsein Bassal4, Ziad Salameh5: Evaluation of the Adaptation and Fracture Resistance of Three CAD-CAM Resin Ceramics: An In vitro StudyThe Journal of Contemporary Dental Practice .2019: 10.5005

45. Emam N Z and AleemAN: Influence of different materials and preparation designs on marginal adaptation and fracture resistance of cad/cam fabricated occlusal veneers; EDJ; vol. 66, no. 1

46. Leung B, Tsi J, Matinlinna J, Pow E. Comparison of mechanical properties of three machinable ceramics with an experimental fluorophlogopite glass ceramic. J Prosthet Dent. 2015; 114:440-446.

47. El Ghoul W ,x Özan X, Silwadi M , Salameh Z: Fracture resistance and failure modes of endocrowns manufactured with different $\mathrm{CAD} / \mathrm{CAM}$ materials under axial and lateral loading. J Esthet Restor Dent. 2019; 1-10.

48. Magne P, Schlichting LH, Maia HP, Baratieri LN. In vitro fatigue resistance of CAD/CAM composite resin and ceramic posterior occlusal veneers. J Prosthet Dent. 2010; 104(3):149-157.

49. Komiyama O, Obara R, Iida T.: Comparison of direct and indirect occlusal contact examinations with different clenching intensities. J Oral Rehabil; 2015, 42: 185-191. 